\title{
Determination of polythionates in an active crater lake by nitrate ion-selective electrode
}

\author{
Yoshiko Fujiwara, Shinji OHSAWa, Kunihiko Watanuki \\ and BOKUICHIRO TAKANO \\ Department of Chemistry, College of Arts and Sciences, \\ University of Tokyo, Komaba, Meguro-ku, Tokyo 153, Japan \\ (Received December 27, 1988; Accepted February 9, 1989)
}

\begin{abstract}
A nitrate ion-selective electrode, Orion model 93-07, has been examined to determine in situ tri- to hexathionate in an active crater lake. The electrode (ISE) showed a linear response to aqueous polythionates within a range of $10^{-5}-10^{-2} \mathrm{M}$. The slope in the plot of log concentration vs electrode potential was slightly larger than the Nernst slope for $\mathrm{S}_{3} \mathrm{O}_{6}^{2-}, \mathrm{S}_{4} \mathrm{O}_{6}^{2-}$ and $\mathrm{S}_{5} \mathrm{O}_{6}^{2-}$, while a considerably larger one was observed for $\mathrm{S}_{6} \mathrm{O}_{6}^{2-}$. Selectivity coefficients determined by the fixed interference method were $k_{34}^{\text {pot }}=23, k_{45}^{\text {pot }}=10$ and $k_{56}^{\text {pot }}=7.0$ for a pair of $\mathrm{S}_{3} \mathrm{O}_{6}^{2-}-\mathrm{S}_{4} \mathrm{O}_{6}^{2-}, \mathrm{S}_{4} \mathrm{O}_{6}^{2-}-\mathrm{S}_{5} \mathrm{O}_{6}^{2-}$ and $\mathrm{S}_{5} \mathrm{O}_{6}^{2-}-\mathrm{S}_{6} \mathrm{O}_{6}^{2-}$, respectively. The observed variation in the electrode potential for polythionate solution was best explained in terms of the Nicholsky-Eisenman equation. Chloride and sulfite ions less than $2500 \mathrm{ppm}$ and $500 \mathrm{ppm}$, respectively, did not interfere with the potential measurement. The sum of three polythionates (tetraplus penta- plus hexathionate) of volcanic origin determined by the ISE method has agreed well with those by the microbore column HPLC.
\end{abstract}

\section{INTRODUCTION}

Mt. Kusatsu Shirane is an active volcano located in the western Gunma Prefecture, at which 17 eruptions have been recorded since the 19th century (Minakami, 1939). The crater lake of the volcano, Yugama $\left(7.90 \times 10^{5} \mathrm{~m}^{3}\right.$, Ito et al., 1981), contains a large amount of hydrochloric and sulfuric acids of which total acidity is almost $0.1 \mathrm{M}$. There are five effervescent subaqueous fumaroles in the crater lake (Shimoya, 1985), which continuously discharge $\mathrm{SO}_{2}$ and $\mathrm{H}_{2} \mathrm{~S}$ gases. These gases dissolve in the water and react to yield a lot of sulfur species in intermediate oxidation states. Thus such species in waters of volcanic origin will be useful indicators for monitoring volcanic activities. Takano (1987) demonstrated that polythionates in the Yugama water behave regularly with the Kusatsu-Shirane volcanic activity. In the 1982-1983 eruptions the level of polythionates began to rapidly decrease at least two months before the eruptions, and finally fell below the analytical detection limit just before the first explosion. This phenomenon has been explained by the following reaction (1):

$$
\begin{array}{r}
\mathrm{S}_{x+1} \mathrm{O}_{6}^{2-}+\mathrm{HSO}_{3}^{-} \rightleftarrows \mathrm{S}_{x} \mathrm{O}_{6}^{2-}+\mathrm{S}_{2} \mathrm{O}_{3}^{2-}+\mathrm{H}^{+} \\
(n>=3) .
\end{array}
$$

As previously noted by Iwasaki et al. (1962) and reconfirmed by Hirabayashi (1984) for Mt. Kusatsu Shirane, increasing volcanic activity is accompanied by an increase in the $\mathrm{SO}_{2} / \mathrm{H}_{2} \mathrm{~S}$ ratio of the gas. Under such a circumstance the equilibrium of the reaction (1) shifts toward right, finally resulting in polythionate decomposition. Although the reaction involving such sulfur species in Yugama must be more complicated, it would seem to be summarized as follows:

$$
\begin{array}{r}
\mathrm{S}_{x} \mathrm{O}_{6}^{2-}+(3 x-7) \mathrm{HSO}_{3}^{-} \longrightarrow(2 x-3) \mathrm{SO}_{4}^{2-} \\
+(2 x-4) \mathrm{S}+(x-1) \mathrm{H}^{+}+(x-3) \mathrm{H}_{2} \mathrm{O} .
\end{array}
$$


If this interpretation is reasonable, the variation of polythionates in Yugama would have a close relationship with this volcano's activity through the $\mathrm{SO}_{2} / \mathrm{H}_{2} \mathrm{~S}$ ratio of the subaqueous fumarolic gas. We have used a microbore column HPLC to separate and determine these thionates. But this method requires a sizable instrumentation and can not directly be applied to the in situ analysis of the lake water.

Tuovinen and Nicholas (1977) reported that the commercially-available ion selective electrode for nitrate ion (nitrate ISE) showed a response to tri- and tetrathionate. Analysis of the water by the nitrate ISE is easy, not expensive and especially convenient for the in situ determination of polythionates.

In this paper, we have characterized the response of the nitrate ISE to tri-, tetra-, pentaand hexathionate and applied it to the determination of polythionates (tetra- plus penta- plus hexathionate) in the Yugama crater lake water.

\section{EXPERIMENTAL}

Potential measurement: A nitrate ISE (Orion Model 93-07) was used in conjunction with a Ross reference electrode (Orion Model 80-05) which showed more rapid response to temperature variation than a sleeve-type $\mathrm{Ag} / \mathrm{AgCl}$ electrode. Electrode potentials were measured with an Orion Model SA 520 digital pH/mV temperature meter.

Solutions were stirred gently using a DC stirrer with a teflon-coated magnetic spin bar in order to get quick and stable potential readings. All the experimental conditions were directed toward the natural condition for the Yugama crater lake water. Solution temperature was set at $21-22^{\circ} \mathrm{C}$. Ionic strength and $\mathrm{pH}$ were adjusted to 0.15 and 1.3 , respectively, by a bisulfatesulfate buffer. All polythionates except trithionate are considerably stable around this pH (Kurtenacker et al., 1935). Potential readings were taken within 5-10 minutes when they became stable. To remove an asymmetry potential of the ISE meter, it was calibrated to $-\mathbf{1 5 5 . 0}$ $\mathrm{mV}$ by an $0.10 \mathrm{M}$ sodium nitrate solution before each measurement. The temperature dependence of the ISE was at the level of $+0.6,+0.6$ and $+0.9 \mathrm{mV} /{ }^{\circ} \mathrm{C}$ for tetra-, penta- and hexathionate, respectively, within a temperature range of $3-20^{\circ} \mathrm{C}$. Also, approximately +1 $\mathrm{mV} /{ }^{\circ} \mathrm{C}$ was obtained for the Yugama water which was a mixed solution of each polythionate. A plot of ISE electrode potentials and polythionate concentrations (Fig. 3) was obtained for the Yugama waters by using the analytical data by the microbore HPLC method described below.

Reagents: All the chemicals were reagent grade, used without further purification. Polythionates were synthesized according to Kurtenacker and Matejka (1930), Stamm et al. (1941), Stamm et al. (1942) and Goehring and Feldmann (1948). Each compound was recrystallized once. The purities of potassium tri-, tetra- and pentathionate were better than $95 \%$ and that of potassium hexathionate was $80 \%$. Major impurity in the salts was $\mathrm{KCl}$ which was determined by ion chromatography.

Selectivity coefficient: The coefficient, $k_{i j}^{\text {pot }}$, was determined by the fixed interference method (Covington, 1979), for three pairs of polythionates: trithionate-tetrathionate $\left(k_{34}^{\text {pot }}\right)$, tetrathionate-pentathionate $\left(k_{45}^{\text {pot }}\right)$ and pentathionate-hexathionate $\left(k_{56}^{\text {pot }}\right)$. Coefficients for any other pairs of higher thionate homologues were not determined because the concentrations of such thionates are usually very low in natural water and furthermore their pure salts have not been obtained. The above three coefficients were determined in the solution containing $7.4 \times 10^{-5}$ $\mathrm{M}$ of $\mathrm{S}_{4} \mathrm{O}_{6}^{2-}, 8.2 \times 10^{-5} \mathrm{M}$ of $\mathrm{S}_{5} \mathrm{O}_{6}^{2-}$ and $6.2 \times 10^{-5} \mathrm{M}$ of $\mathrm{S}_{6} \mathrm{O}_{6}^{2-}$, respectively.

Simulated monitoring of aqueous polytionates by $\mathrm{NO}_{3}^{-}$ISE: The potential readings were taken at $60^{\circ} \mathrm{C}$ in $3 \mathrm{~L}$ of the Yugama water of the initial polythionate concentrations: $\mathrm{S}_{4} \mathrm{O}_{6}^{2-}, 118$ ppm; $\mathrm{S}_{5} \mathrm{O}_{6}^{2-}, 86.8 \mathrm{ppm} ; \mathrm{S}_{6} \mathrm{O}_{6}^{2-}, 36.0 \mathrm{ppm}$. Five molar sodium hydroxide and $1 \mathrm{M}$ sodium bisulfite solutions were added dropwise from 
time to time to accelerate the degradation of polythionates. Not more than $500 \mathrm{ppm}$ of sulfite ions were added to avoid the interference by the ions. The $\mathrm{pH}$ values of the solution changed from 1.54 to 3.32 during the potential measurement. For the determination of each polythionate concentration by the microbore column HPLC (described below), the solution was sampled at the same time as the potentials were read.

Microbore column HPLC: Tetra-, penta- and hexathionates were determined by the HPLC with a microbore column $(1 \mathrm{~mm}$ i.d. $\times 100 \mathrm{~mm}$ length) packed with silica based ODS in $3 \mu$ particle size (Spherisorb 3-ODS-2). The mobile phase for separation was $0.1 \mathrm{M}$ potassium dihydrogen phosphate solution $(\mathrm{pH}=3.5)$ with $0.1 \%(\mathrm{v} / \mathrm{v})$ tetra-n-butylammonium hydroxide. The solution contained acetonitrile (chromatographic grade) of $25 \mathrm{v} / \mathrm{v} \%$. Details of the method were described in Takano and Watanuki (1988).

\section{Results AND Discussion}

\section{Response to polythionate}

The Orion nitrate ISE responded linearly to the logarithm of the concentration of polythionates within a range of $10^{-5}-10^{-2} \mathrm{M}$ (a few thousands ppm to a few ppm). On the other hand, this electrode showed a response proportional to nitrate concentration only within a range of $10^{-3}-10^{-1} \mathrm{M}$ (Fig. 1). The difference between the potential readings in stirred and still solutions was found to be less than a few millivolts in the range of the measured polythionate concentration. At a concentration of a polythionate lower than $10^{-5} \mathrm{M}$, reproducibility in the potential readings became poor, together with a large deviation from the Nernst slope for divalent ions.

Selectivity coefficients $\left(k_{i j}^{\text {pot }}\right)$ determined in

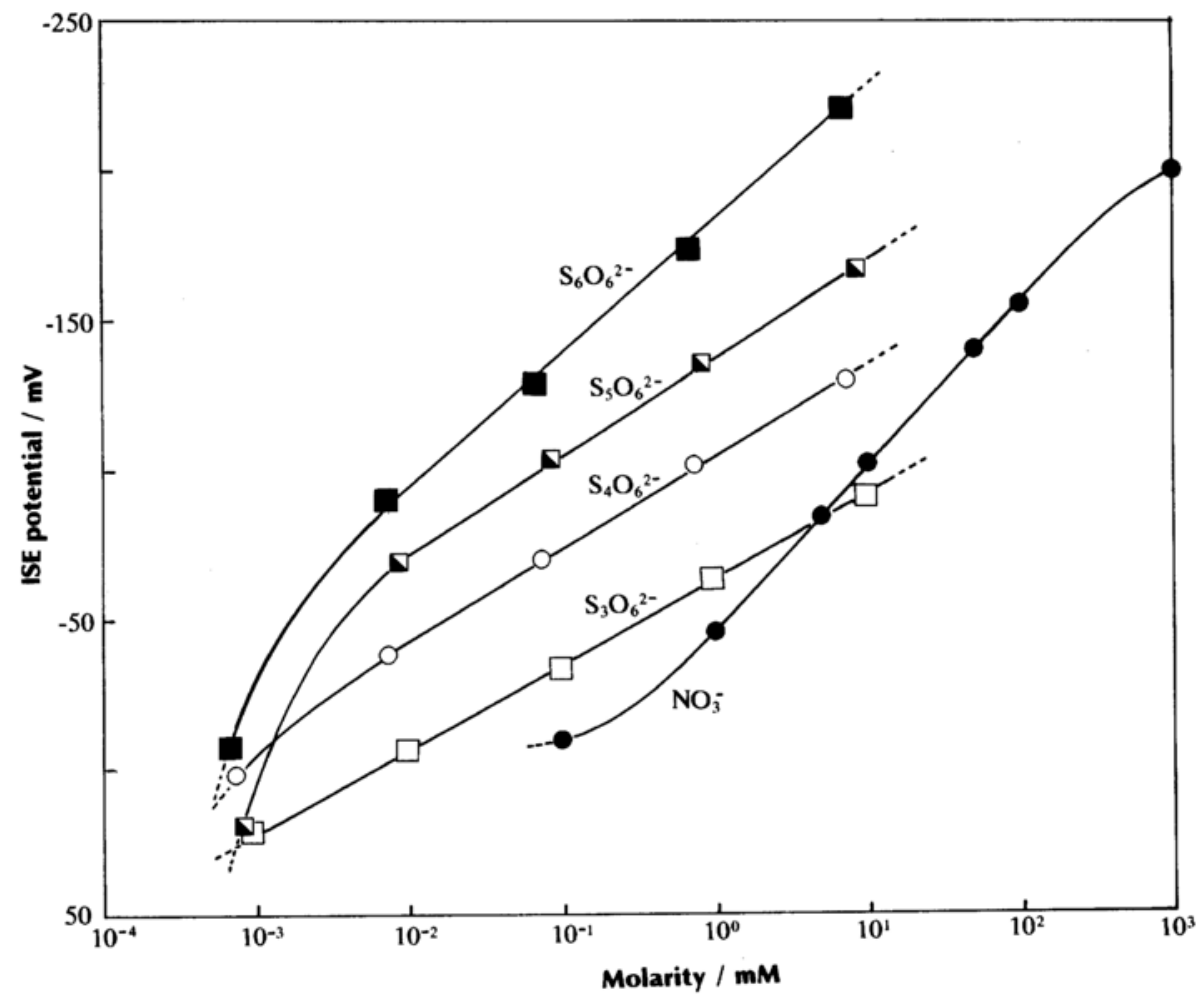

Fig. 1. Response of the nitrate ISE (Orion 93-07) to polythionates. The ionic strength and pH values of the polythionate and nitrate solutions are $0.15,1.28$ and $0.15,7.0$, respectively. 
the present work for each combination of thionates with $i$ and $j$ atoms of sulfur are

$$
k_{34}^{\text {pot }}=23, k_{45}^{\text {pot }}=10 \text { and } k_{56}^{\text {pot }}=7.0 .
$$

For example, $k_{34}^{\text {pot }}=23$ means that the electrode is 23 times more sensitive to $\mathrm{S}_{4} \mathrm{O}_{6}^{2-}$ than to $\mathrm{S}_{3} \mathrm{O}_{6}^{2-}$. These coefficients show that the nitrate ISE is more sensitive to polythionates of a longer sulfur chain. The potential reading at a lower polythionate concentration $\left(<10^{-4} \mathrm{M}\right)$ became constant 10 minutes after immersion of the electrode to the test solution and the time to reach $95 \%$ of the equilibrium potential was 5 minutes. At higher concentrations this electrode responded more quickly. Reproducibility in potential readings is shown in Table 1 . The lower the concentrations and the longer the $\mathrm{S}$ chain in polythionates were, the higher coefficients of variation were observed. In general, the errors inherent in the ISE methods of analysis are considered to be of the order of a few percent (Umezawa, 1983). Subsequently, the electrode potential readings are considered to be
Table 1. Reproducibility in electrode potential measurements

\begin{tabular}{lccrrr}
\hline Species & $\begin{array}{c}\text { Concentra- } \\
\text { tion } \\
(\mathrm{M})\end{array}$ & $\begin{array}{c}\text { Number } \\
\text { of } \\
\text { measure- } \\
\text { ment }\end{array}$ & $\begin{array}{c}\text { Mean } \\
(\mathrm{mV})\end{array}$ & $\begin{array}{c}\text { Standerd } \\
\text { deviation }\end{array}$ & C.V.\% \\
\hline $\mathrm{S}_{4} \mathrm{O}_{6}^{2-}$ & $7.4 \times 10^{-3}$ & 5 & -129.3 & 1.3 & 1.0 \\
& $7.4 \times 10^{-5}$ & 4 & -70.8 & 1.5 & 2.1 \\
$\mathrm{~S}_{5} \mathrm{O}_{6}^{2-}$ & $8.2 \times 10^{-3}$ & 5 & -165.9 & 1.1 & 0.7 \\
& $8.2 \times 10^{-6}$ & 3 & -71.0 & 2.0 & 2.8 \\
$\mathrm{~S}_{6} \mathrm{O}_{6}^{2-}$ & $6.2 \times 10^{-3}$ & 4 & -216.3 & 3.7 & 1.7 \\
& $6.2 \times 10^{-6}$ & 5 & -92.9 & 4.2 & 4.5 \\
\hline
\end{tabular}

Ionic strength $=0.15, p H=1.28$, temperature $=21-22^{\circ} \mathrm{C}$, stirring.

sufficiently reproducible. Orion Model 93-07 is an electrode of liquid ion exchanger type with a PVC membrane. After repeated measurements, for example, for $50 \mathrm{~h}$ under repeated usage, the electrode became less sensitive to polythionate in low concentration probably because of loss of the liquid exchanger and deformation of the membrane resulting in the decrease in Nernst slope. The electrode can be regenerated not fully

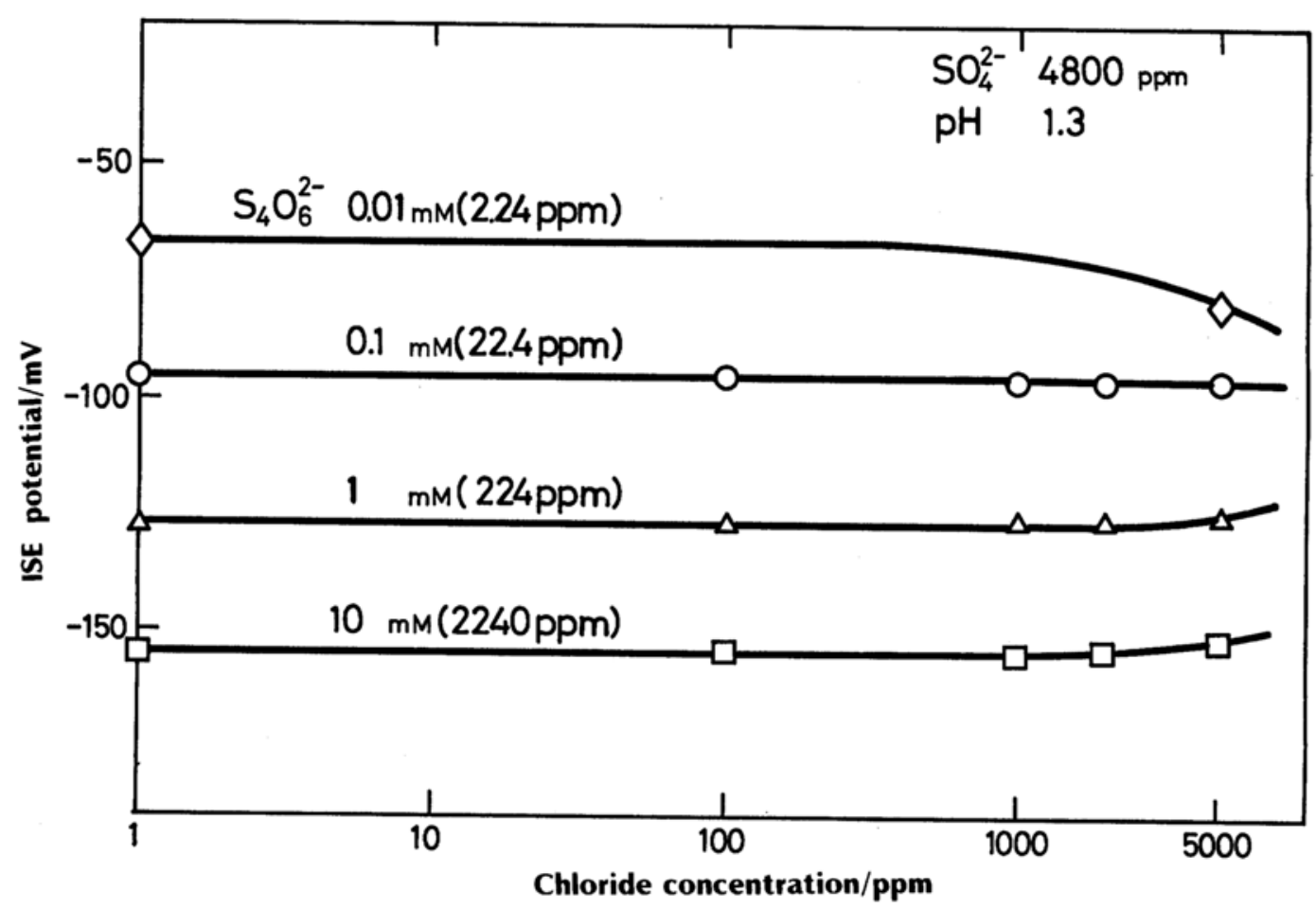

Fig. 2. Effect of chloride ion on electrode potential in acidic tetrathionate solution. 
but partially after its long immersion into a $1 \mathrm{M}$ sodium nitrate solution. We did not, however, use such a regenerated electrode for this experiment, because of its short lifetime.

Effect of coexisting anions, $p H$ and ionic strength on electrode response

We examined the effect of chloride and sulfurous ions upon the electrode potential. The electrode practically does not respond at all to sulfuric acid: it is used as an ionic strength adjusting solution (Orion Instruction Manual). Thiosulfate ion, being unstable under acidic condition (Haff, 1970), was not tested. The potential readings were taken after adding a chloride solution to polythionate solution. Figure 2 shows that chloride less than $2500 \mathrm{ppm}$ gave no change in potential readings even when the level of polythionate was less than $10^{-5} \mathrm{M}$. It was also found that sulfurous acid did not interfere up to
$500 \mathrm{ppm}$ (unpublished data). Sulfurous acid in natural water is present at an insignificantly low level, and therefore it does not interfere either. Negligible potential variation was observed for the test solution when $\mathrm{pH}$ and ionic strength changed from 1.0 to 1.9 and 0.1 to 0.2 , respectively.

Electrode response to polythionates in the Yugama water

A linear regression of the logarithms of the sum of three polythionates (tetra- plus pentaplus hexathionate) $(X)$ against potential readings by the nitrate ISE $(Y)$ gave a best fit equation ( $r=-0.991$, Fig. 3),

$$
Y=-88.9-34.9 X \text {. }
$$

Using eq. (4), polythionates in some Yugama waters were determined with no stirring of the test solution. Comparison of the results by ISE

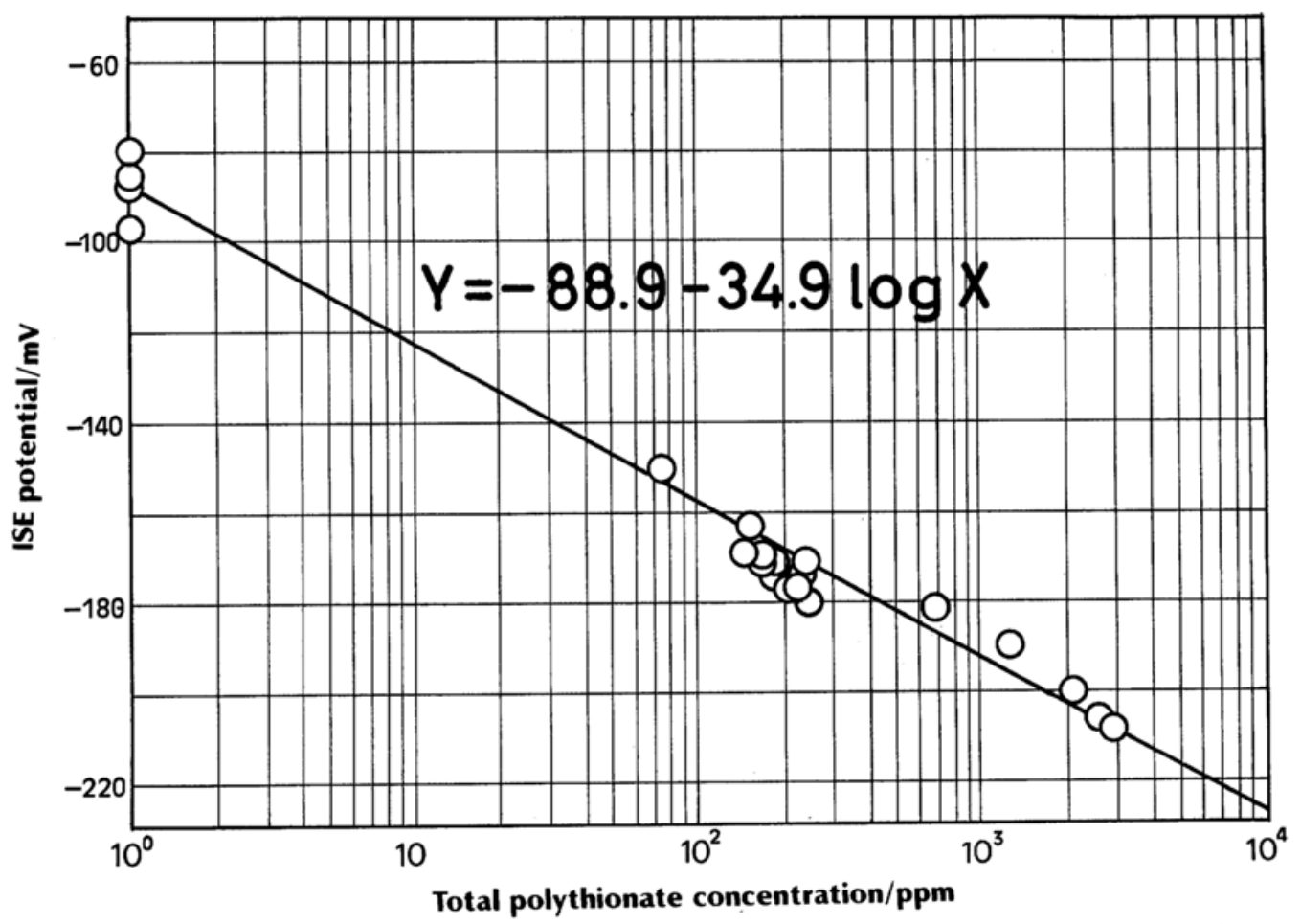

Fig. 3. Relationship between electrode potential and "total polythionates" (see text) in the Yugama water. Measurements were made for stationary solution. Each polythionate was determined by the microbore column HPLC. Correlation coefficient of the plot was -0.991 . The slope of the plot in molar scale is in good agreement with the one expected from Fig. 1 . 
Table 2. Determination of total polythionates in Yugama water by nitrate ion-selective electrode

\begin{tabular}{cccc}
\hline Sample No. & Potential/mV & ISE/ppm & HPLC/ppm \\
\hline 860923 & $-161.0^{a}$ & 116 & 116 \\
860930 & $-157.0^{b}$ & 104 & 113 \\
860930 & $-160.7^{c}$ & 114 & $107^{d}$ \\
\hline
\end{tabular}

${ }^{a}$ measured in the laboratory at water temperature of $26.9^{\circ} \mathrm{C}$; sample was delivered by a commercial delivery service.

${ }^{b}$ measured in situ at water temperature of $20^{\circ} \mathrm{C}$.

${ }^{\text {' } m e a s u r e d ~ t h r e e ~ d a y s ~ a f t e r ~ s a m p l i n g ~ i n ~ t h e ~ l a b o r a t o r y ~ a t ~}$ water temperature of $25.7^{\circ} \mathrm{C}$; sample was delivered by the authors.

${ }^{d}$ meausred in situ; the whole analytical system was transported to the Kusatsu-Shirane visitor station, about $500 \mathrm{~m}$ from the Yugama crater lake. method and microbore column HPLC (Table 2) indicates that they are in good agreement and no serious systematic errors are found between the laboratory and the in situ determinations.

These facts strongly suggest that the nitrate ISE, at least an Orion 93-07 electrode, can be used as a sensor for the determination of the sum of three polythionates (tetra- plus penta- plus hexathionate) in the Yugama water. Distinct from the microbore HPLC, the ISE technique in this experiment cannot quantify each polythionate. For in situ monitoring, however, the latter method is much more advantageous for its small instrumentation and easy manipula-

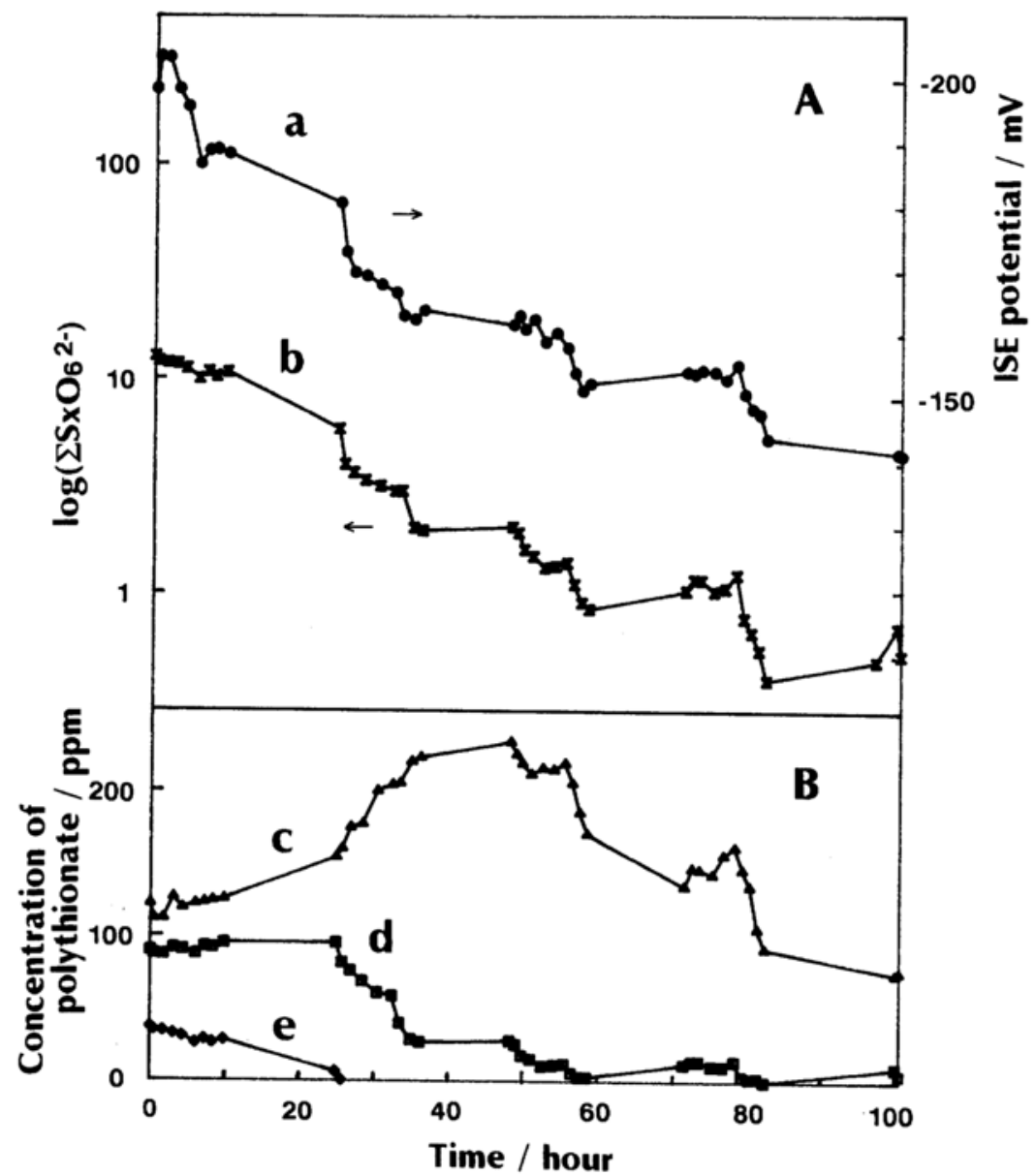

Fig. 4. A: (a) Variation of ISE potential during polythionate decomposition. (b) Variation of $\log \left(\Sigma S_{x} O_{6}^{2-}\right)$. $\Sigma S_{x} \mathrm{O}_{6}^{2-}$ is a linear combination of polythionate concentration multiplied by selectivity coefficient (eq. (6)). B: Variation of polythionate concentration as a function of time. (c) tetrathionate, (d) pentathionate, (e) hexathionate. 
tion.

\section{Polythionate monitoring by ISE}

A simulation experiment was conducted to evaluate how fast and accurately the change in "total polythionates" in the Yugama water is followed by the nitrate ISE. Figure 4B shows the variation in each polythionate, which was determined by the microbore column HPLC. Although each polythionate changes in different way, the ISE potential always increases (Fig. 4A, a). Due to the analytical incapability, however, we do not know "total polythionates" in the water. Subsequently the term "total polythionates" in the following discussion means the sum of tetra-, penta- and hexathionates. Trithionate has not been detected in the Yugama water and was at negligible level in the simulation solution from the potential measurement view. Thus trithionate in the solution was neglected in the discussion. Using eq. (3), the electrode potential for "total polythionates" $\left(E_{t}\right)$ can be expressed by the Nicholsky-Eisenman equation (Covington, 1979),

$$
E_{t}=\text { constant }+k \log \left(\Sigma \mathrm{S}_{x} \mathrm{O}_{6}^{2-}\right)
$$

where $k$ is a constant and,

$$
\Sigma \mathrm{S}_{x} \mathrm{O}_{6}^{2-}=\left[\mathrm{S}_{4} \mathrm{O}_{6}^{2-}\right]+10\left[\mathrm{~S}_{5} \mathrm{O}_{6}^{2-}\right]+70\left[\mathrm{~S}_{6} \mathrm{O}_{6}^{2-}\right]
$$

Chemical species in bracket denote concentrations in $\mathrm{mM}$. When $\log \left(\mathrm{S}_{x} \mathrm{O}_{6}^{2-}\right)$ is plotted against time, the mode of variation in Fig. 4A(b) coincides well with that of nitrate ISE potentials in Fig. 4A(a). This fact strongly indicates that the electrode can catch fast and accurately enough the change in "total polythionates" in the Yugama water.

Preliminary experiments showed that higher polythionates are subjected to sulfitolysis (Wagner and Schreier, 1978) much faster than lower homologues (one of the authors YF, unpublished data). This means that polythionates in the water decreased in the following order,

$$
\mathrm{S}_{6} \mathrm{O}_{6}^{2-} \longrightarrow \mathrm{S}_{5} \mathrm{O}_{6}^{2-} \longrightarrow \mathrm{S}_{4} \mathrm{O}_{6}^{2-} \text {. }
$$

In addition, the decrease in hexathionate, as sug- gested by Fig. 1 and eqs. (5) and (6), will give the greatest increase in potential readings. Accordingly, when excess sulfur dioxide gas is intensively injected into the Yugama water through subaqueous fumaroles, as often observed in the active period of the volcano, the first polythionate being decomposed is expected to be hexathionate. Under such circumstance, the nitrate ISE will show a greater positive jump in potential and indicate a magmatic resurgence triggering an increase in the flux of rising gases.

\section{Conclusions}

The nitrate ISE, Orion 93-07, works as a sensor for polythionates in acidic crater lake waters. There are practically no interfering ions in water of volcanic origin except for sulfite ions more than $500 \mathrm{ppm}$. Although durability of the electrode in such a strongly acidic water is not satisfactory enough for continuous surveillance of active crater lake, it is quite convenient for frequent monitoring of such a crater lake in situ.

\section{REFERENCES}

Covington, A. K. (1979) Introduction: Basic electrode type, classification, and selectivity considerations. Ion-Selective Electrode Methodology. CRC Press. United States, Boca Raton, Florida. 15p.

Goerhing, M. and Feldmann, U. (1948) Neue Verfahren zur Darstellung von Kaliumpentathionat und von Kaliumhexathionat. Z. anorg. allg. Chem. 257, 223-226.

Haff, L. V. (1970) Oxygen containing inorganic sulfur compounds. The Analytical Chemistry of Sulfur and its Compounds. Part I. ed. Karchmer, J. H., Interscience Publishers. New York, London, Sydney, Toronto. 232p.

Hirabayashi, J. (1984) Variation in composition of volcanic gas and volcanic activities (in Japanese). $\mathrm{Ph}$ D dissertation, Tokyo Institute of Technology.

Ito, Y., Saito, T. and Sekioka, M. (1981) Morphometry and thermometry of crater lake Yugama, Volcano Kusatsu Shirane, in the eastern Japan. Part I: Measurements in the summer of 1978. $J$. Geotherm. Res. Soc. Japan 3, No. 1, 1-14 (Japanese).

Iwasaki, I., Ozawa, T., Yoshida, M., Katura, T., Iwasaki, B., Kamada, M. and Hirayama, M. (1962) 
Volcanic gases in Japan. Bull. Tokyo Inst. Technol. No. 47, 1-54.

Kurtenacker, A. and Matejka, K. (1930) Über die Darstellung von Tetra- und Trithionat aus Thiosulfat und Schwefliger Säure. Z. anorg. allg. Chem. 193, 367-384.

Kurtenacker, A. Nutschin, A. and Stastny, F. (1935) Über die Selbstzersetzung von Polythionatlösungen. Z. anorg. allog. Chem. 224, 339419.

Minakami, T. (1939) Explosive activities of Volcano Kusatu-Shirane during 1937 and 1938. Bull. Earthq. Res. Inst. 17, 591-622.

Shimoya, M. (1985) Observation of Shirane Volcano, Jyoumou Shinbun, Maebashi (in Japanese).

Stamm, H., Goehring, M. and Feldmann, U. (1942) Zur Kenntnis der Polythionsäuren und ihrer Bildung. Z. anorg. allg. Chem. 250, 226-228.

Stamm, H., Seipold, O. and Goehring, M. (1941) Die
Darstellung von K-penta- und -hexathionat. $Z$. anorg. allg. Chem. 247, 281-306.

Takano, B. (1987) Correlation of volcanic activity with sulfur oxyanion speciation in a crater lake. Science 235, 1633-1635.

Takano, B. and Watanuki, K. (1988) Quenching and liquid chromatographic determination of polythionates in natural water. Talanta 35, 847854.

Tuovinen, O. H. and Nicholas, D. J. D. (1977) Bacterial oxidation of polythionates; Determination of tetrathionate with an ion-selective electrode. Appl. Envioron. Microbiol. 33, 477-479.

Umezawa, Y. (1983) Ion selective electrode (in Japanese). Gendai Kagaku No. 146, 50-58.

Wagner, H. and Schreier, H. (1978) Investigation on the sulfite degradation of polythionates. Phosphorus and Sulfur 4, 285-286. 